\title{
com \\ Comparative Study of Cold Sintering Process and Autoclave Thermo-Vapor Treatment on a ZnO Sample
}

\author{
Yurii Ivakin ${ }^{1,2}$, Andrey Smirnov ${ }^{2, *}$, Anastasia Kholodkova ${ }^{1} \oplus$, Alexander Vasin ${ }^{2}$, Mikhail Kormilicin ${ }^{2}$, \\ Maxim Kornyushin ${ }^{2}$ and Vladimir Stolyarov ${ }^{3}$ \\ 1 Chemistry Department, M. V. Lomonosov Moscow State University, 119991 Moscow, Russia; \\ ivakin@kge.msu.ru (Y.I.); anastasia.kholodkova@gmail.com (A.K.) \\ 2 Mobile Solutions Engineering Center, MIREA-Russian Technological University, 119454 Moscow, Russia; \\ alexandrvasin123@gmail.com (A.V.); kmihail2013@yandex.ru (M.K.); maksim.korn0312@yandex.ru (M.K.) \\ 3 Department of Friction and Wear, Mechanical Engineering Research Institute of RAS, 101990 Moscow, Russia \\ vlstol@mail.ru \\ * Correspondence: smirnov_av@mirea.ru
}

check for

updates

Citation: Ivakin, Y.; Smirnov, A.; Kholodkova, A.; Vasin, A.; Kormilicin, M.; Kornyushin, M.; Stolyarov, V. Comparative Study of Cold Sintering Process and Autoclave Thermo-Vapor Treatment on a ZnO Sample. Crystals 2021, 11, 71. https://doi.org/ $10.3390 /$ cryst11010071

Received: 20 December 2020 Accepted: 14 January 2021 Published: 16 January 2021

Publisher's Note: MDPI stays neutral with regard to jurisdictional clai$\mathrm{ms}$ in published maps and institutional affiliations.

Copyright: (C) 2021 by the authors. Licensee MDPI, Basel, Switzerland. This article is an open access article distributed under the terms and conditions of the Creative Commons Attribution (CC BY) license (https:// creativecommons.org/licenses/by/ $4.0 /)$.

\begin{abstract}
Analysis of scanning electron microscopy images was used to study the changes in the crystal size distribution of $\mathrm{ZnO}$, which occurred during its processing in an aqueous medium at $220-255^{\circ} \mathrm{C}$ and an equilibrium vapor pressure in an autoclave. The results were compared with those of $\mathrm{ZnO}$ placed in a die for treatment under similar conditions supplemented with mechanical pressure application in the cold sintering process. In both cases, $\mathrm{ZnO}$ was treated in the presence of an activating additive: either zinc acetate or ammonium chloride. During autoclaving, a powder consisting of fine $\mathrm{ZnO}$ monocrystals was obtained, while the cold sintering process led to ceramics formation. Under vapor pressure and mechanical pressure, the aqueous medium affected $\mathrm{ZnO}$ transformation by the same mechanism of solid-phase mobility activation due to the additives' influence. The higher the content of additives in the medium, and the higher the mechanical pressure, the more pronounced activating effect was observed. Mass transfer during the cold sintering process occurred mainly by the coalescence of crystals, while without mechanical pressure, the predominance of surface spreading was revealed. In the initial $\mathrm{ZnO}$ powder, the average crystal size was $0.193 \mu \mathrm{m}$. It grew up to $0.316-0.386 \mu \mathrm{m}$ in a fine-crystalline powder formed in the autoclave and to an average grain size of $0.244-0.799 \mu \mathrm{m}$ in the ceramics, which relative density reached $0.82-0.96$. A scheme explaining the influence of an aqueous medium on the solid-phase mobility of $\mathrm{ZnO}$ structure was proposed. It was found that the addition of $7.6 \mathrm{~mol} \%$ ammonium chloride to the reaction medium causes the processes of compaction and grain growth similar to those observed in ZnO Cold Sintering Process with the addition of $0.925 \mathrm{~mol} \%$ zinc acetate.
\end{abstract}

Keywords: oxide ceramics; zinc oxide; cold sintering process; thermo-vapor treatment; solid-phase mobility in a water medium; crystal size distribution; coalescence; surface spreading

\section{Introduction}

Recent studies have shown that the sintering temperatures of oxide ceramics in the presence of water decrease from the region above $100{ }^{\circ} \mathrm{C}$ to the range of $200-400{ }^{\circ} \mathrm{C}[1,2]$. The sintering of dense ceramics of simple and complex oxides at a low temperature due to the presence of water is called the cold sintering process (CSP) [3]. For example, the sintering temperature of $\mathrm{ZnO}$ ceramics is lowered by hundreds of degrees (from $>1000{ }^{\circ} \mathrm{C}$ to $<200{ }^{\circ} \mathrm{C}$ ), and the sintering time is significantly reduced. It was found $[4,5]$ that the presence of acetates contributes to the sintering of $\mathrm{ZnO}$. In [6], the CSP of ZnO ceramics was carried out at a temperature of $240{ }^{\circ} \mathrm{C}$ in a medium of $20 \%$ acetic acid solution $(1.6 \mathrm{~mol} \%$ $\mathrm{CH}_{3} \mathrm{COOH}$ by weight of $\mathrm{ZnO}$ ). To explain the effect of the acidic medium of an aqueous solution on mass transfer during sintering, the idea of the dissolution of stressed areas and the release of $\mathrm{ZnO}$ in the contact region of particles is usually used [7-12]. When 
discussing the results of CSP in several works [7,13-16], the insufficiency of the dissolutionreprecipitation mechanism for understanding the processes occurring during sintering of oxides with the participation of water is noted. The necessity of searching for scientific bases for the choice of activating additives for various oxide materials is also justified [7].

Additional information about the processes occurring in the interaction of simple and complex oxides with the water medium is provided by studies of transformations under hydrothermal or thermo-vapor conditions of autoclave treatment (TVT). First of all, it should be noted that when processing occurs in a water medium in an autoclave without applying mechanical pressure, a sharp decrease in the temperature of oxide transformations is also observed (Table 1). In studies of the synthesis and changes in the dispersion of simple and complex oxides in water vapor, as well as in the medium of sub- and supercritical water fluid [17-19], ideas have been formed about the mechanisms of the processes that can be used to interpret the effect of mechanical pressure on the mass transfer processes during cold sintering.

Table 1. Influence of the aquatic environment on the oxide's transformations temperature.

\begin{tabular}{clccc}
\hline & Transformation & & Without Water, ${ }^{\circ} \mathbf{C}$ & $\begin{array}{c}\text { TVT in the Aquatic } \\
\text { Environment, }{ }^{\circ} \mathbf{C}\end{array}$ \\
\hline $2 \mathrm{Al}(\mathrm{OH})_{3}$ & $\rightarrow$ & $\alpha-\mathrm{Al}_{2} \mathrm{O}_{3}$ & $1100-1200[20]$ & $400[21-23]$ \\
$2 \mathrm{AlOOH}$ & $\rightarrow$ & $\mathrm{ZnAl}_{2} \mathrm{O}_{4}$ & $800[24]$ & $180[25]$ \\
$\mathrm{ZnO}+\mathrm{Al}_{2} \mathrm{O}_{3}$ & $\rightarrow$ & $\mathrm{BaTiO}_{3}$ & $1300[26]$ & $200[17]$ \\
$\mathrm{BaO}+\mathrm{TiO}_{2}$ & $\rightarrow$ & $\mathrm{MgAl}_{2} \mathrm{O}_{4}$ & $1400[27,28]$ & $400[29]$ \\
$\mathrm{MgO}+\mathrm{Al}_{2} \mathrm{O}_{3}$ & $\rightarrow$ & recrystal. $\mathrm{ZnO}$ & $650-750[30]$ & $100[19]$ \\
$\mathrm{ZnO}$ & $\rightarrow$ & &
\end{tabular}

In this work, the effect of two activating additives-zinc acetate $\left(\mathrm{Zn}\left(\mathrm{CH}_{3} \mathrm{COO}\right)_{2} \cdot 2 \mathrm{H}_{2} \mathrm{O}\right)$ and ammonium chloride $\left(\mathrm{NH}_{4} \mathrm{Cl}\right)$ - on the recrystallization of $\mathrm{ZnO}$ during autoclave treatment in water vapor under free powder filling conditions and under CSP in a similar environment, but with the application of mechanical pressure, was studied. The selection of adjuvants was made based on results of experiments on recrystallization of $\mathrm{ZnO}$ to the source powder in the environment of water vapor at temperatures of $100-400{ }^{\circ} \mathrm{C}$ (TVT) in the presence of activator located on the surface of particles or in water vapor, which leads to a change of dispersion with the formation of fine crystalline $\mathrm{ZnO}$ powder [19]. Activation of the transformation occurs when zinc chloride and ammonium chloride are applied to the surface of $\mathrm{ZnO}$ particles [19] or the hydrolysis products of chlorides, acetates, and crystalline iodine are transferred to the water vapor medium [19], which are placed with water on the bottom of the autoclave outside the container with dry $\mathrm{ZnO}$ powder. The activating agent is the corresponding volatile acid. The interaction of acid protons with $\mathrm{ZnO}$ leads to an increase in hydroxyl groups' concentration in its structure, formed during the dissociative adsorption of water molecules from the environment. Hydroxyl groups do not form stable compounds with $\mathrm{ZnO}$ under TVT conditions $[19,31,32]$ and are released into the gas phase, forming water molecules. The intensive transition of water molecules from the gas medium to the $\mathrm{ZnO}$ structure and back leads to numerous local rearrangements and the formation of defects in the crystal structure, which determine the appearance of solid-phase mobility. Due to the different frequency of local rearrangements of the oxide matrix, structural positions with an increased lifetime (the time between the appearance of the position and its rearrangement during the exchange of water molecules with the medium) accumulate, and the crystal lattice is improved [17-19]. As a result, an ordered $\mathrm{ZnO}$ structure is formed with a smooth surface of well-cut crystals. Also, in the medium of water vapor or water fluid, during prolonged exposure of the formed fine crystalline $\mathrm{ZnO}$, there is a redistribution of mass, and a change in the powder's disperse composition, i.e., recrystallization occurs [19]. A dense ceramic structure is formed during mechanical uniaxial pressing of $\mathrm{ZnO}$ powder in a low-density water-acetate medium $[6,33]$. 
The present work aims to investigate the effect of mechanical pressure on the change in the dispersion of $\mathrm{ZnO}$ powder during processing in water vapor in the presence of various additives that activate mass transfer between crystals. It is assumed that the determination of micro additives' activity in the processes of mass redistribution under conditions of increased temperature and pressure of the water medium in the autoclave can contribute to the optimization of the water medium composition and the CSP conditions of oxide ceramics.

\section{Materials and Methods}

In the present work was used dispersed fine crystalline $\mathrm{ZnO}$ powder with an average particle size of $0.193 \mu \mathrm{m}$, zinc acetate $\left(\mathrm{Zn}\left(\mathrm{CH}_{3} \mathrm{COO}\right)_{2} \cdot 2 \mathrm{H}_{2} \mathrm{O}\right)$, and ammonium chloride $\left(\mathrm{NH}_{4} \mathrm{Cl}\right)$. All reagents had a content of the main component of more than $99 \%$.

For $\mathrm{ZnO}$ preparation with the applied activator, $20 \mathrm{~g}$ of the powder was mixed in an ultrasonic bath with $30 \mathrm{~mL}$ of the activator solution in distilled water. The suspension was dried at a temperature not exceeding $70^{\circ} \mathrm{C}$ for $12 \mathrm{~h}$. Then the dried mass was crushed in an agate mortar and sifted through a sieve with holes of $300 \mu \mathrm{m}$.

CSP was carried out in a steel mold with induction heating (Figure 1). The advantage of induction heating is a higher heating rate and less thermal inertia of the structure. However, this heating method is less manageable in setting the set temperature values. The mold contained four punches (with a diameter of $17 \mathrm{~mm}$ ), between which $\mathrm{ZnO}$ powder was located in the middle, and between the other punches, the Teflon seals rings were placed. The seals were used to prevent water from squeezing out and evaporating through the gaps in the mold during the pre-compaction of the mixture for $1 \mathrm{~h}$ at a pressing pressure of $396 \mathrm{MPa}$. Two grams of $\mathrm{ZnO}$ powder were poured into the mold with the lower pair of punches and $0.4 \mathrm{~mL}$ of water was added with careful mixing ( $20 \%$ of the mass of $\mathrm{ZnO}$ ). Then the second pair of punches was lowered into the mold. A hot junction of the thermocouple was fixed to the mold in a recess near the sample. The mold with the heater was installed along the axis of the hydraulic press. The powder's shrinkage in the mold was controlled by measuring the axial displacement of the lower platform of the hydraulic press with a mechanical movement indicator of the clock type (with a division price of $10 \mu \mathrm{m}$ ) fixed on a fixed frame. The CSP modes and compositions of the initial mixtures are presented in (Table 2).

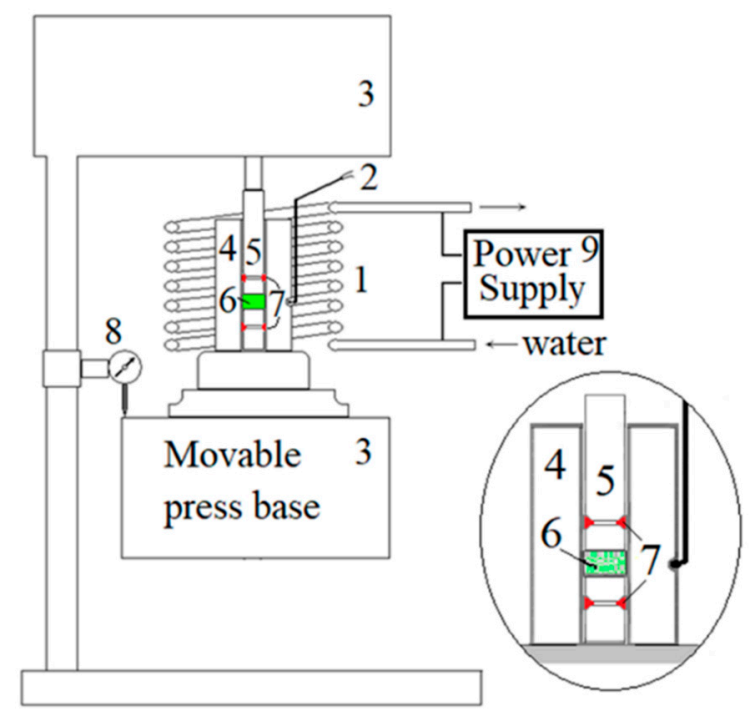

Figure 1. The CSP setup: 1-coil induction heater; 2-thermocouple; 3-hydraulic press; 4-die mold; 5-set of punches; 6-ZnO powder; 7—seal rings; 8-motion sensor; 9-Power Supply. 
Table 2. The CSP conditions.

\begin{tabular}{cccccc}
\hline Sample \# & Additive; mol \% & $\begin{array}{c}\text { Pressing (Compaction, 1 h), } \\
\text { MPa }\end{array}$ & $\begin{array}{c}\text { Pressing (Dwell), } \\
\text { MPa }\end{array}$ & TDwell, ${ }^{\circ} \mathbf{C}$ & Dwell Time, min \\
\hline CSP1 & $\mathrm{Zn}(\mathrm{Ac})_{2} \cdot 2 \mathrm{H}_{2} \mathrm{O} ; 0.185$ & 396 & 77 & 220 & 60 \\
$\mathrm{CSP} 2$ & $\mathrm{Zn}(\mathrm{Ac})_{2} \cdot 2 \mathrm{H}_{2} \mathrm{O} ; 0.927$ & 396 & 77 & 255 & 60 \\
$\mathrm{CSP3}$ & $\mathrm{NH}_{4} \mathrm{Cl} ; 4.56$ & 396 & 396 & 246 & 60 \\
$\mathrm{CSP} 4$ & $\mathrm{NH}_{4} \mathrm{Cl} ; 7.6$ & 396 & 396 & 255 & 60 \\
\hline
\end{tabular}

TVT of $\mathrm{ZnO}$ powder was performed in laboratory autoclaves with a volume of $17 \mathrm{~mL}$ with a copper sealing gasket and using Teflon containers with a lid on a free fit. The container was installed in an autoclave on a stand. Water was poured into the bottom of the autoclave below the container on the stand. A sample of $\mathrm{ZnO}$ powder with an activator applied by impregnation to the particles' surface was placed in the container. At such loading of the autoclave, heating and isothermal $\mathrm{ZnO}$ holding took place in water vapor or in sub- and supercritical water fluid and corresponded to the conditions of TVT (Figure 2). The features of filling the autoclave with water are described in [19]. The conditions for processing zinc oxide in an autoclave are presented in Table 3 . The additive content in the reaction medium was calculated in molar percentages relative to the mass of $\mathrm{ZnO}$.

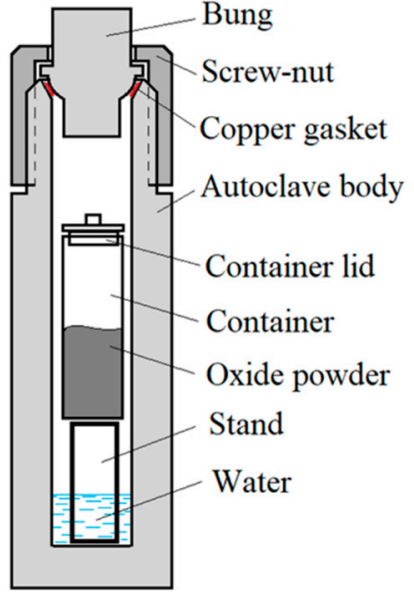

(a)

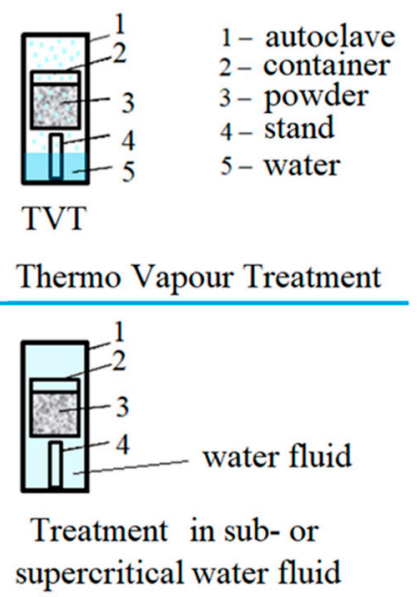

(b)

Figure 2. The TVT setup: (a)—autoclave scheme; (b)—differences between TVT and sub- or supercritical water fluid treatment.

Table 3. The TVT conditions.

\begin{tabular}{ccccccc}
\hline Sample \# & Additive; mol\% & $\begin{array}{c}\text { Water Inside the } \\
\text { Container; } \mathbf{~ m L}\end{array}$ & $\begin{array}{c}\text { Water Outside } \\
\text { Container; } \mathbf{~ m L}\end{array}$ & $\begin{array}{c}\text { Vapor Pressure; } \\
\mathbf{M P a}\end{array}$ & T; ${ }^{\circ} \mathbf{C}$ & Dwell Time; h \\
\hline TVT1 & $\mathrm{Zn}(\mathrm{Ac})_{2} \cdot 2 \mathrm{H}_{2} \mathrm{O} ; 0.185$ & - & 1 & 3.46 & 240 & 26 \\
TVT2 & $\mathrm{Zn}(\mathrm{Ac})_{2} \cdot 2 \mathrm{H}_{2} \mathrm{O} ; 0.927$ & - & 1 & 3.46 & 240 & 24 \\
TVT3 & $\mathrm{NH}_{4} \mathrm{Cl}_{4} 4.56$ & - & 1 & 3.46 & 240 & 14 \\
TVT4 & $\mathrm{NH}_{4} \mathrm{Cl} ; 7.6$ & - & 1 & 3.46 & 240 & 14 \\
\hline
\end{tabular}

The relative density of ceramics was determined by the Archimedean method. The morphology of ceramic powders and chips was studied using a JSM-6390 LA scanning electron microscope (JEOL Ltd., Tokyo, Japan). The size distribution of powder crystals and grains of CSP ceramic samples was determined by analyzing images [18] obtained with a scanning electron microscope (SEM). The average size of crystals and grains was determined by simply averaging over all measured objects in the sample. The Image-Pro software was used to determine the size of 2000 to 3000 particles in each sample. Due to 
a large number of measured particles, the measurement error was less than $1 \%$ (Table 4). The phase composition of the samples was studied on an XRD-6000 X-ray diffractometer (Shimadzu Corp., Kyoto, Japan) with $\mathrm{CuK} \alpha$ radiation and the wavelength of the secondary radiation $\left(\lambda=1.54 \AA\right.$ ) with a graphite monochromator in the range of $20^{\circ} \leq 2 \theta \leq 70^{\circ}$ with step $2 \theta=0.02^{\circ}$. The voltage is $50 \mathrm{kV}$, the cathode glow current is $250 \mathrm{~mA}$. Scanning speed $5 \% / \mathrm{min}$. The samples phases composition was determined by comparing the experimental data with the data of the PDF-2 database.

\section{Results}

Figure 3 shows the SEM image and the crystal size distribution of the initial $\mathrm{ZnO}$ powder. The total average crystal size is $0.193 \mu \mathrm{m}$. These results are used as initial data for evaluating the processes of crystal growth in TVT and densification and grain growth in CSP.

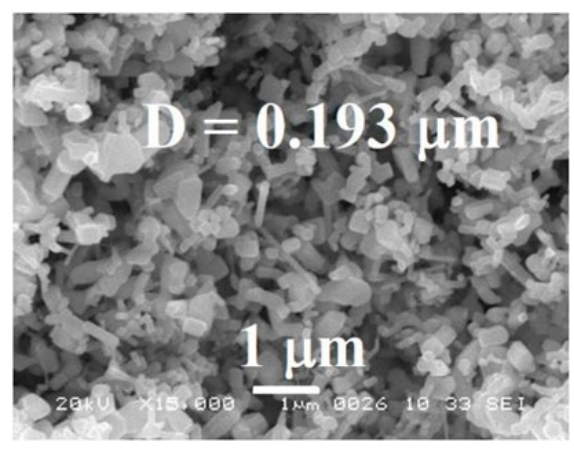

(a)

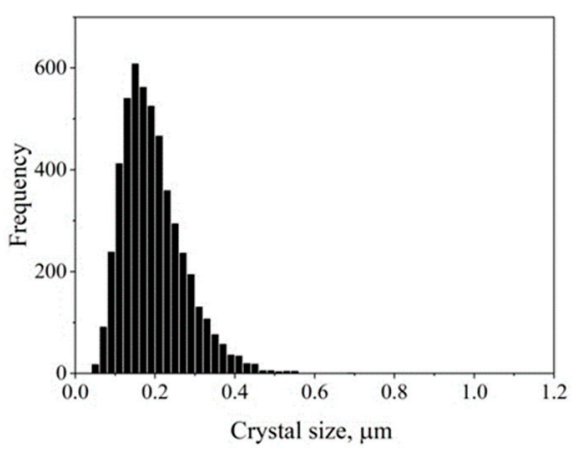

(b)

Figure 3. Characteristics of the initial ZnO powder: (a) SEM micrograph (Reprinted from Ref. [33], copyright (2019), with the kind permission of Springer Nature.); (b) crystal size distribution.

Figure 4 shows a comparison of SEM images of microstructure of samples CSP1 and CSP2 obtained in the CSP and samples of powders TVT1 and TVT2 obtained in TVT with an identical amount of zinc acetate.

Comparing the analysis results of the microstructure of CSP and TVT of ZnO samples with the addition of ammonium chloride is shown in Figure 5. The distribution of particle sizes in the samples obtained by TVT and the grain sizes of CSP samples is shown in Figure 6.

Figure 7 shows $\mathrm{X}$-ray patterns of samples obtained in a medium of zinc acetate-sample CSP1 (a) and the presence of an additive of $7.6 \mathrm{~mol} \% \mathrm{NH}_{4} \mathrm{Cl}$ - sample CSP4 (b), as well as sample TVT4 (c). The X-ray pattern of sample CSP1 in the range $2 \theta=10-70^{\circ}$ contains only characteristic reflexes of the $\mathrm{ZnO}$ structure of wurtzite. There are no extraneous reflexes (Figure 7a). The X-ray pattern in Figure $7 \mathrm{c}$ refers to the TVT4 sample with the same amount of ammonium chloride added in the CSP4 sample. In addition to the $\mathrm{ZnO}$ reflexes, low-intensity reflexes are visible, which, as in [19], belong to the $\mathrm{Zn}_{5}(\mathrm{OH})_{8} \mathrm{Cl}_{2} \mathrm{H}_{2} \mathrm{O}$ (JCPDS 7-155) phase, formed after TVT ZnO at $240{ }^{\circ} \mathrm{C}$ (Table 3). The appearance of the $\mathrm{Zn}_{5}(\mathrm{OH})_{8} \mathrm{Cl}_{2} \mathrm{H}_{2} \mathrm{O}$ phase with a decomposition temperature of $250{ }^{\circ} \mathrm{C}$ was observed in [34] and also in [10]. On the X-ray pattern of the CSP4 sample (Figure 7b), unidentified traces of the decay product of this phase are marked with a round icon. 


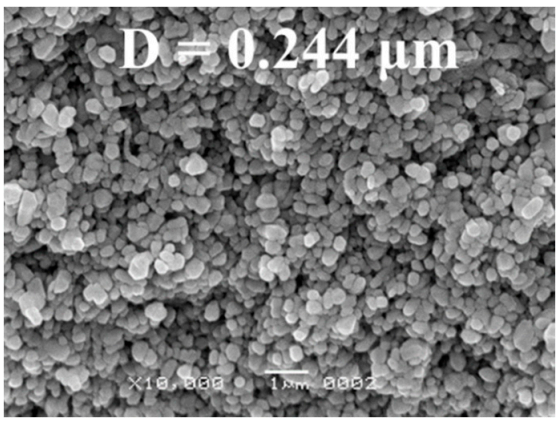

(a)

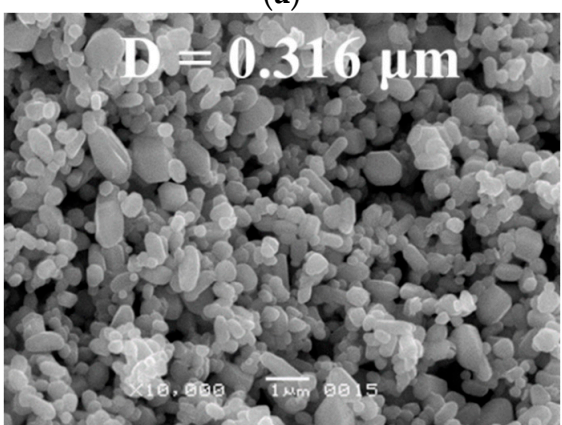

(c)

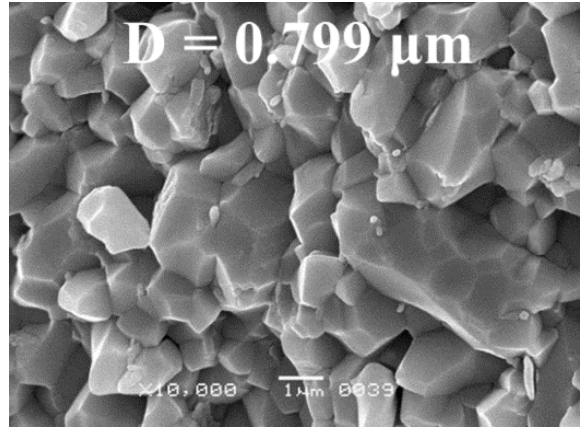

(b)

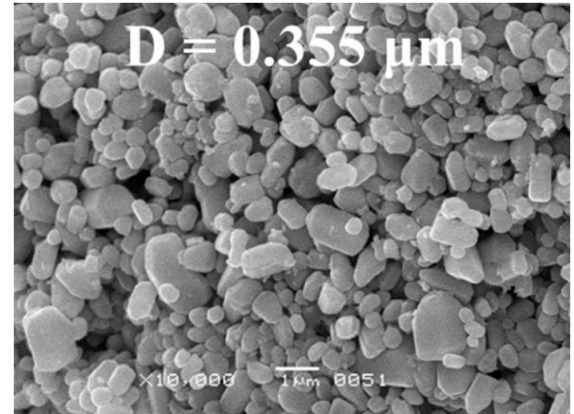

(d)

Figure 4. Microstructure of samples obtained in an acetate medium: (a) CSP1 sample $(0.185 \mathrm{~mol} \%$ $\left.\mathrm{Zn}(\mathrm{Ac})_{2}\right)$; (b) CSP2 sample (0.927 mol\% Zn(Ac) $)_{2}$ (Reprinted from Ref. [33], copyright (2019), with the kind permission of Springer Nature.); (c) TVT1 sample (0.185 mol\% Zn(Ac) $)_{2}$; (d) TVT2 sample $\left(0.927 \mathrm{~mol} \% \mathrm{Zn}(\mathrm{Ac})_{2}\right)$.

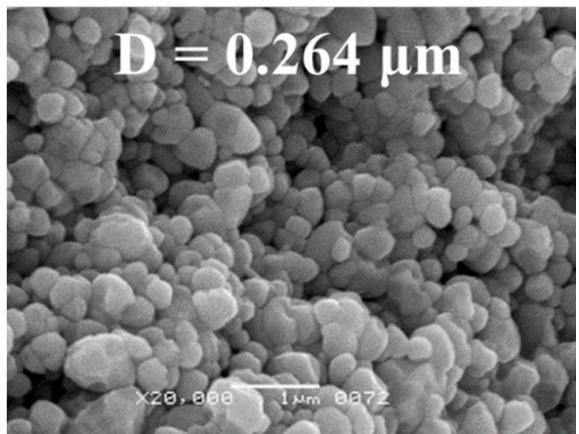

(a)

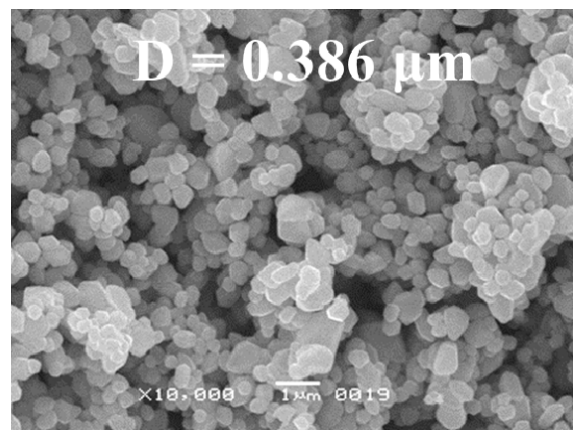

(c)

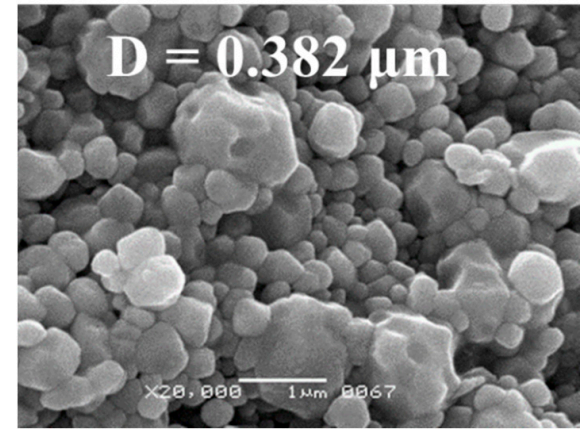

(b)

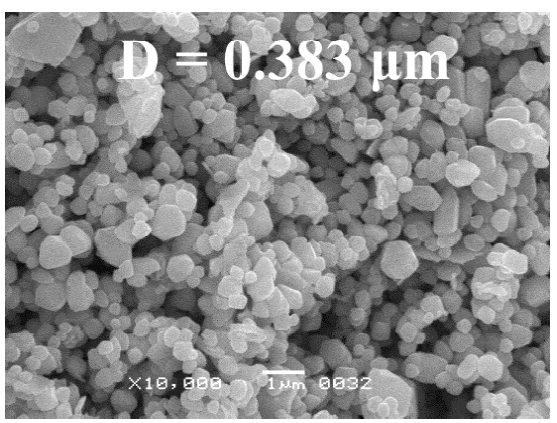

(d)

Figure 5. Microstructure of CSP and TVT samples, additive-ammonium chloride: (a) CSP3 sample (4.56 mol\% $\mathrm{NH}_{4} \mathrm{Cl}$ ); (b) CSP4 sample (7.6 mol\% $\left.\mathrm{NH}_{4} \mathrm{Cl}\right)$; (c) TVT3 sample $\left(4.56 \mathrm{~mol}^{\circ} \mathrm{NH}_{4} \mathrm{Cl}\right.$ ); (d) TVT4 sample $\left(7.6 \mathrm{~mol}^{\circ} \mathrm{NH}_{4} \mathrm{Cl}\right)$. 


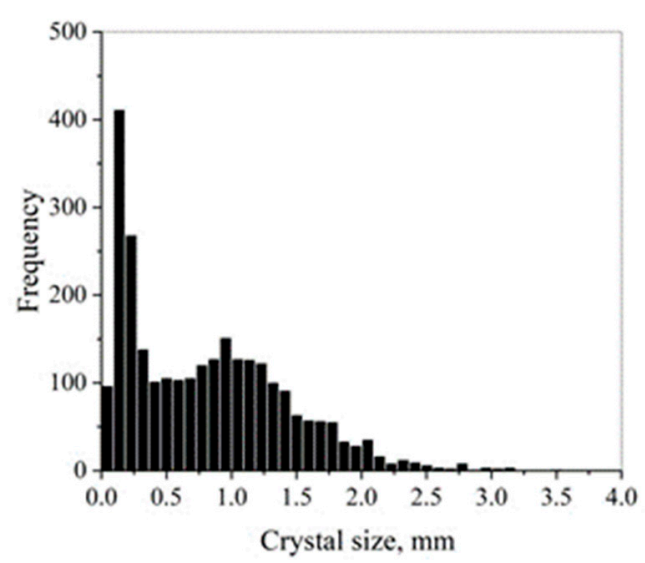

(a)

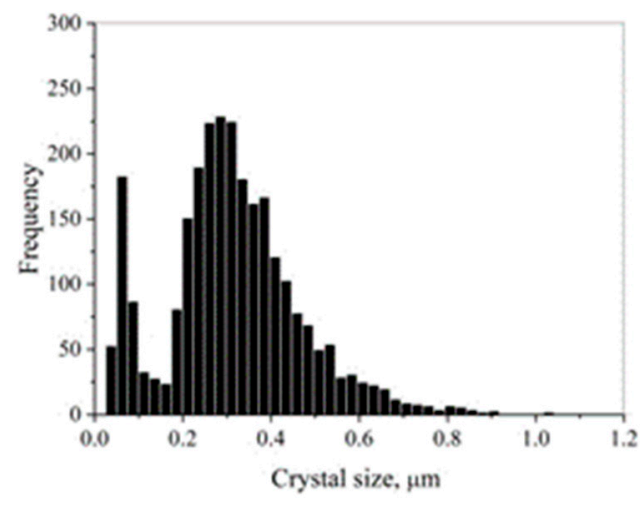

(c)

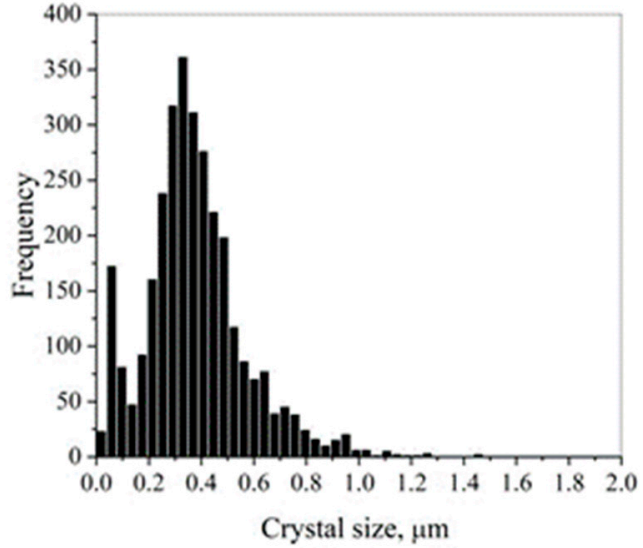

(b)

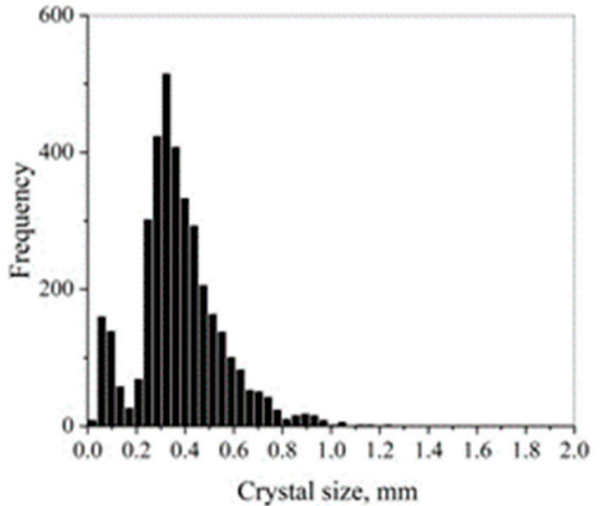

(d)

Figure 6. Grain size distribution of samples after CSP and crystals size distribution after TVT: (a) CSP2 (0.927 mol\% Zn(Ac) 2$)$; (b) CSP4 (7.6 $\left.\mathrm{mol}_{\%} \mathrm{NH}_{4} \mathrm{Cl}\right)$; (c) TVT2 (0.927 mol\% $\left.\mathrm{Zn}(\mathrm{Ac})_{2}\right)$; (d) TVT4 (7.6 $\left.\mathrm{mol} \% \mathrm{NH}_{4} \mathrm{Cl}\right)$.

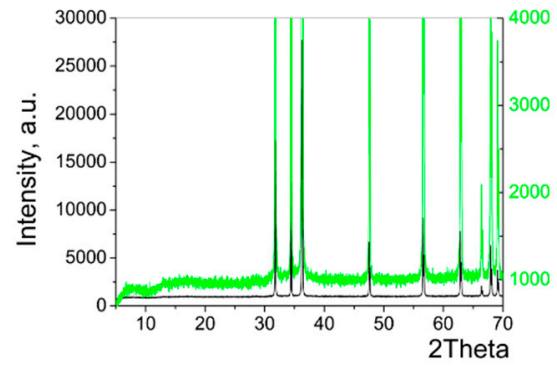

(a)

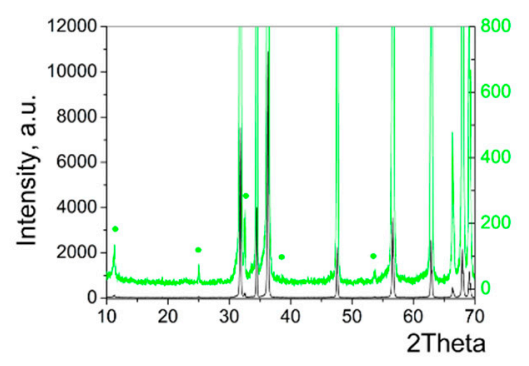

(b)

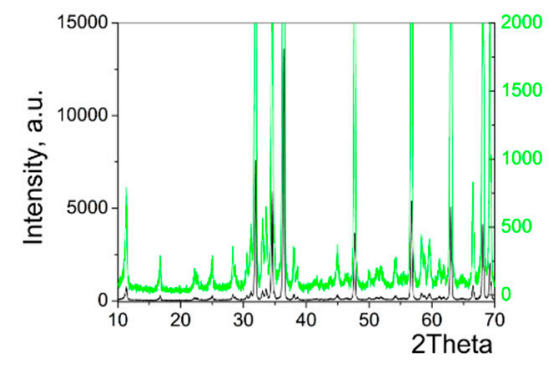

(c)

Figure 7. X-ray patterns of samples: (a) CSP1; (b) CSP4; (c) TVT4: black—full spectrum; green-the spectrum is shown with increased sensitivity for the low-intensity reflexes detection; green dots-reflexes of unidentified phase.

The results of the experiments are summarized in Table 4. For CSP samples, data on the relative density and average grain size are given. For TVT samples, data on the average crystal size are presented. 
Table 4. The experimental results.

\begin{tabular}{cccc}
\hline Sample & Additive; $\mathbf{m o l} \%$ & Mean Grain Size, $\boldsymbol{\mu m}$ & Relative Density \\
\hline $\mathrm{CSP} 1$ & $\mathrm{Zn}(\mathrm{Ac})_{2} \cdot 2 \mathrm{H}_{2} \mathrm{O} ; 0.185$ & $0.244 \pm 0.002$ & $0.83 \pm 0.02$ \\
$\mathrm{CSP} 2$ & $\mathrm{Zn}(\mathrm{Ac})_{2} \cdot 2 \mathrm{H}_{2} \mathrm{O} ; 0.927$ & $0.799 \pm 0.011$ & $0.96 \pm 0.02$ \\
$\mathrm{CSP} 3$ & $\mathrm{NH}_{4} \mathrm{Cl} ; 4.56$ & $0.264 \pm 0.002$ & $0.82 \pm 0.02$ \\
$\mathrm{CSP} 4$ & $\mathrm{NH}_{4} \mathrm{Cl} ; 7.6$ & $0.382 \pm 0.004$ & $0.91 \pm 0.02$ \\
\hline Sample & Additive; $\mathbf{m o l} \%$ & Mean Crystal Size, $\boldsymbol{\mu m}$ \\
\hline TVT1 & $\mathrm{Zn}(\mathrm{Ac})_{2} \cdot 2 \mathrm{H}_{2} \mathrm{O} ; 0.185$ & $0.316 \pm 0.003$ \\
TVT2 & $\mathrm{Zn}(\mathrm{Ac})_{2} \cdot 2 \mathrm{H}_{2} \mathrm{O} ; 0.927$ & $0.355 \pm 0.004$ \\
TVT3 & $\mathrm{NH}_{4} \mathrm{Cl} ; 4.56$ & $0.386 \pm 0.003$ \\
TVT4 & $\mathrm{NH}_{4} \mathrm{Cl} ; 7.6$ & $0.383 \pm 0.003$ \\
\hline
\end{tabular}

\section{Discussion}

A comparative study of the effect of activating additives on the CSP and TVT processes of fine-crystalline $\mathrm{ZnO}$ powder was carried out based on the hypothesis of similarity of the two processes' conditions under consideration. The CSP3 sample obtained at CSP with the addition of $4.56 \mathrm{~mol} \% \mathrm{NH}_{4} \mathrm{Cl}$ in a mold with Teflon sealing rings had a residual moisture content of $0.2 \%$ (residual water weight $0.0034 \mathrm{~g}$ ). In a dry sample with a mass of $1.6582 \mathrm{~g}$ and a relative density of 0.82 , the volume of the gaps between the crystals is $0.065 \mathrm{~cm}^{3}$. At $250{ }^{\circ} \mathrm{C}, 0.0013 \mathrm{~g}$ of water evaporates into the interstices' volume in the form of saturated steam [35]. The remaining $0.0021 \mathrm{~g}$ of water occupies $4 \%$ of the volume of the gaps. Thus, when the working volume is reduced during pressing, the main part of the initially added water $(0.4 \mathrm{~mL})$ is squeezed out, and the powder is compacted in a water vapor environment. Due to this, the interaction of $\mathrm{ZnO}$ with water vapor at TVT in an autoclave and CSP in a mold with Teflon sealing rings occurs under similar conditions, except for the influence of mechanical pressing pressure.

Figure 4 compares the SEM images and the size distribution of ceramics' cleavage zones after CSP and crystals after TVT. The crystals of the TVT1 sample are noticeably larger than the grains on the CSP1 ceramic chip, but in both cases have a similar morphology of rounded particles. At the same time, the grains in the CSP1 sample grew and acquired a rounded morphology in just $1 \mathrm{~h}$ at a temperature of $220^{\circ} \mathrm{C}$ and a pressing pressure of 77 $\mathrm{MPa}$, and the crystal growth time of the TVT1 sample was $26 \mathrm{~h}$ at a temperature of $240^{\circ} \mathrm{C}$ and a water vapor pressure of $3.46 \mathrm{MPa}$. This result indicates that the level of activator content of $0.185 \mathrm{~mol} \%$ zinc acetate in the reaction medium was sufficient for slow mass transfer but insufficient for the appearance of structure mobility, at which it is possible to fill the space with the formation of a forced cut of crystalline grains of ceramics. A comparison of the microstructure of the cleavage of the CSP2 sample and the morphology of the crystals of the TVT2 sample obtained at $0.927 \mathrm{~mol} \%$ zinc acetate shows that the increased content of the activator in the reaction medium led to almost complete filling of the space with the formation of a forced grain cut (average size $0.799 \mu \mathrm{m}$ ) and obtaining ceramics with a high relative density (0.96; Table 4$)$. The mechanism of rapid mass transfer between crystals with a mobile structure is coalescence. The pressing pressure of $77 \mathrm{MPa}$ and a temperature of $255^{\circ} \mathrm{C}$ for $60 \mathrm{~min}$ were sufficient for consolidation under the influence of a sufficient amount of zinc acetate and water vapor. Under TVT ZnO conditions with $0.927 \mathrm{~mol} \%$ zinc acetate at a temperature of $240{ }^{\circ} \mathrm{C}$ and a water vapor pressure of $3.46 \mathrm{MPa}$, the crystals grew to an average size of $0.355 \mu \mathrm{m}$ in $24 \mathrm{~h}$, which is significantly inferior to the average grain size in the CSP2 sample but exceeds the average crystal size of the TVT1 sample. Consequently, in a water vapor medium at temperatures of $220-255^{\circ} \mathrm{C}$, a slow mass transfer occurs, the mechanism of which under the influence of mechanical pressure turns into coalescence.

It should be noted that a similar slow mass transfer between $\mathrm{ZnO}$ crystals was observed when the samples were stored in a humid atmosphere at room temperature [36-38] and $85^{\circ} \mathrm{C}$ [39]. According to our ideas, the change in the dispersion of $\mathrm{ZnO}$ powder during storage in a humid atmosphere or application of an additive from an aqueous solution is 
explained by the mobility of the crystal structure in a water medium [19]. An increase in mass transfer with an increase in the additive content when zinc acetate is applied indicates an increase in the mobility of the structure of $\mathrm{ZnO}$ crystals.

Figure 5 shows the results of CSP and TVT of $\mathrm{ZnO}$ with $\mathrm{NH}_{4} \mathrm{Cl}$ additive. The ceramics fractures run along the boundaries between the grains and reveal their morphology. SEM images of CSP and TVT samples show that the bulk of crystals and grains have the same morphology of rounded particles. The TVT3 sample crystals have smooth faces of regular cut and are noticeably larger than the grains of the CSP3 sample. CSP3 ceramic grains are less isometric and can form dense agglomerates with narrow boundaries. With an increase in the additive concentration from $4.56 \mathrm{~mol} \%$ to $7.6 \mathrm{~mol} \%$, the larger grains of the CSP4 sample acquire a forced cut with traces of neighboring small spherical crystals (Figure $5 b$ ). Such crystals with forced cut correspond to the initial stage of growth of ceramic grains. They are formed with the disappearance of boundaries in a dense agglomerate due to the coalescence of neighboring crystals with a mobile structure and flow around crystals with their low mobility. Thus, the compacted microstructure of the CSP 3 sample is formed by changing the shape of grains with a mobile structure. With an increase in the content of the additive from $4.56 \mathrm{~mol} \%$ to $7.6 \mathrm{~mol}^{\circ} \mathrm{NH}_{4} \mathrm{Cl}$ the threshold of the crystal structure mobility is overcome, and coalescence begins, the grain size of ceramics changes (Figure $5 b$ ), the density of ceramics increases (Table 4). Thus, when $7.6 \mathrm{~mol} \% \mathrm{NH}_{4} \mathrm{Cl}$ is applied to the surface of the particles of the initial $\mathrm{ZnO}$ powder under CSP conditions at temperatures of $240-255^{\circ} \mathrm{C}$, pressing pressure of $396 \mathrm{MPa}$ for $60 \mathrm{~min}$, two processes characteristic of sintering ceramics are observed, namely: grain growth and an increase in the density of the initial powder backfill.

For dense $\mathrm{ZnO}$ ceramics formation, a sufficient level of activator content is required, depending on the additive type. Zinc acetate is a more active additive than ammonium chloride and, under the described conditions, leads to sufficient solid-phase mobility of $\mathrm{ZnO}$ crystals for CSP already at $0.927 \mathrm{~mol} \%$. To start the crystals' coalescence in the medium with ammonium chloride under the described conditions, about $7.6 \mathrm{~mol} \% \mathrm{NH}_{4} \mathrm{Cl}$ is required. The type of activating additive also determines the mechanical pressing pressure required for CSP. During cold sintering in an acetate medium, the mode described in [14] was used, in which the powder is first compacted without heating at increased mechanical pressure $(396 \mathrm{MPa})$, then the pressing pressure is reduced to $77 \mathrm{MPa}$, and CSP is carried out at a given temperature. It turned out that in an aqueous medium with the addition of $4.56 \mathrm{~mol} \%$ and $7.6 \mathrm{~mol} \% \mathrm{NH}_{4} \mathrm{Cl}$, CSP occurs at an increased mechanical pressure of $396 \mathrm{MPa}$, i.e., without lowering the pressure after compaction of the powder backfill at room temperature. CSP with the addition of $\mathrm{NH}_{4} \mathrm{Cl}$ requires optimization of conditions and modes to achieve the same values of relative density and grain size as CSP using zinc acetate. Simultaneously, the activating additive $\mathrm{NH}_{4} \mathrm{Cl}$ potentially has an advantage in limiting $\mathrm{ZnO}$ ceramics' grain growth.

Analysis of the grain and crystal size distribution (Figure 6) shows that the close characteristics of the selected fine-dispersed component of the grain distribution of CSP samples and crystals of TVT samples indicate a similar mechanism of its formation. The presence of fine components of the crystal size distribution after TVT and grains after CSP may indicate a slight influence of the dissolution-precipitation mechanism on the processes under consideration. Since, otherwise, the proportion of fine components should not only increase compared to the original fine-crystalline powder (Figure 3) but, on the contrary, should decrease.

Under TVT conditions in the absence of mechanical pressure, the crystal size increases slightly with growth due to the surface spreading of the mass of mobile crystals. When adding mechanical pressure to CSP, under similar conditions, the probability of coalescence of crystals with solid-phase mobility of the structure increases. In this case, both a faster growth of crystalline grains and their compaction with forming a microstructure characteristic of $\mathrm{ZnO}$ ceramics are observed. A summary of the results of a comparative 
study of CSP and TVT of a fine-crystalline $\mathrm{ZnO}$ powder with zinc acetate and ammonium chloride additives previously applied to the surface is schematically presented in Figure 8.

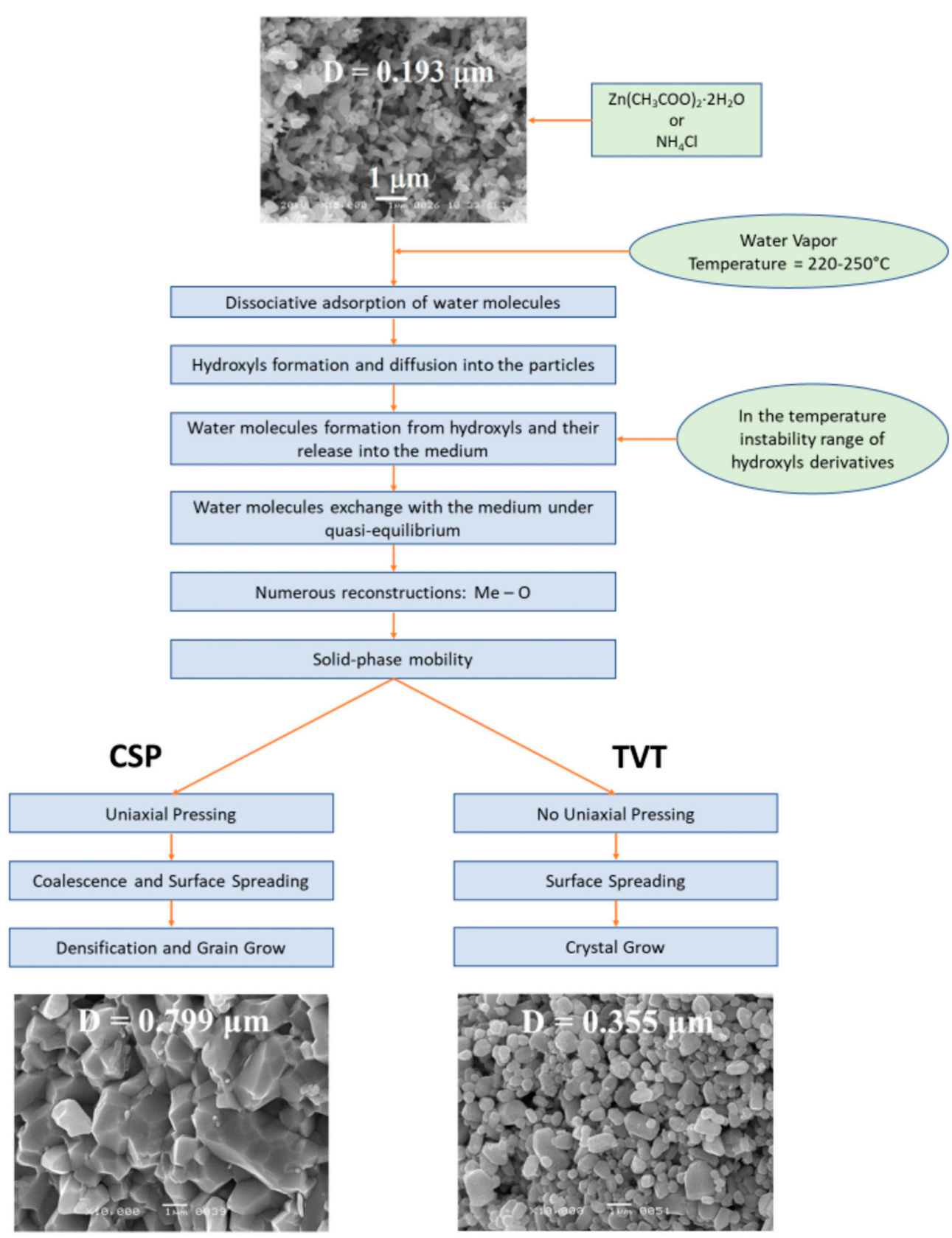

Figure 8. Scheme of the interaction of $\mathrm{ZnO}$ crystals with water vapor in the presence of activating additives in the CSP and TVT processes.

The initial stage of interaction is dissociative adsorption of water molecules [40-44], which leads to hydroxylation of the oxide and disordering of its structure. The resulting hydroxyl groups diffuse into the particle volume. It is assumed that rapid diffusion occurs due to the jump of protons over oxygen ions, both with and without breaking the metal-oxygen bond [45,46]. With the accumulation of hydroxyls, dehydroxylation begins with the formation and release of water molecules into the environment. The dehydroxylation stage occurs in the case of thermal instability of hydroxide compounds in the considered temperature range of transformations. In the study of hydroxylation and dehydroxylation of $\mathrm{ZnO}$ in a water medium, an essential role of proton transport at the interface and in adjacent layers was established [45]. The ratio of the hydroxylation 
and dehydroxylation stages determines the concentration of hydroxyls in the particle volume. When the velocities of hydroxylation and dihydroxylation processes become approximately equal, a quasi-equilibrium of the particle with the medium is established. In this case, depending on the temperature, there is a more or less intensive exchange of water molecules between the water bound in the particle's structure and the environment. The result of the exchange of water molecules is numerous local rearrangements of the structure due to the break and restoration of $\mathrm{Me}-\mathrm{O}$ bonds and the formation of defects and disordering of the structure. The formation of defects and local rearrangements of the structure determines the solid-phase mobility. The more intensive the exchange-the higher the mobility of the structure. The mobility of the surface layer and the volume of the particle should be different. The activating additive in the medium or on the interface affects the hydroxylation, the intensity of the exchange of water molecules, and the degree of solid-phase mobility of the oxide structure.

In the changes of the structure during dehydroxylation local regions that are coherent to the oxide lattice and more defective appear. Defective ones have a lower stability lifetime and are rebuilt more often. As a result, more stable regions accumulate, and the number of defective regions decreases, resulting in an oxide structure ordering. Ordering of the structure leads to a decrease in the content of hydroxyls and the intensity of exchange of water molecules with the medium, leading to a decrease in solid-phase mobility. Due to this, the probability of mass transfer through the surface spreading mechanism decreases. As a result, during the TVT process, crystals morphology changes, and the initial $\mathrm{ZnO}$ crystals' size increases up to a certain limit.

The application of mechanical pressure at CSP brings into contact individual particles of crystalline powder with solid-phase mobility. It increases the probability of coalescence of crystals. Simultaneously, two processes characteristic of sintering ceramics are observed: compaction of the initial powder backfill and grain growth.

\section{Conclusions}

Comparison of the results of changes in the dispersion of the initial $\mathrm{ZnO}$ powder with a crystal size of about $0.193 \mu \mathrm{m}$ under CSP and TVT conditions at similar temperatures showed that in both processes, a mass transfer occurs in water vapor (in a low-density aqueous medium) according to the general mechanism of activation of the solid-phase mobility of the $\mathrm{ZnO}$ crystal structure. The mechanism of mass transfer by dissolutionprecipitation does not play a dominant role in particle growth at TVT and the process of compaction and grain growth at CSP. This is due to the low content of the condensed liquid phase.

At the considered temperatures of TVT and CSP, activation of the solid-phase mobility occurs only in activating additives. At a low content of the additive, dense ceramics formation occurs due to the shape changes of crystals with a mobile structure. An increase in the additive content above a certain threshold leads to coalescence of crystals and the ceramics grain growth. It is shown that the addition of $7.6 \mathrm{~mol} \%$ ammonium chloride to the reaction medium causes the processes of compaction and grain growth similar to those observed in CSP $\mathrm{ZnO}$ with the addition of $0.925 \mathrm{~mol} \%$ zinc acetate ions. Ammonium chloride has a weaker activating effect.

In an aqueous acetate medium, the ceramic grain size and relative density increase from 0.244 to $0.799 \mu \mathrm{m}$ and from 0.83 to 0.96 , respectively, in proportion to the activating additive amount. In an aqueous medium with the addition of ammonium chloride, the grain size of ceramics varies from 0.264 to $0.382 \mu \mathrm{m}$, the relative density from 0.82 to 0.91 with an increase in the content of the additive from 4.56 to $7.6 \mathrm{~mol} \%$. When zinc oxide is processed in water vapor at $240{ }^{\circ} \mathrm{C}$ without mechanical pressure, mass transfer by the surface spreading mechanism occurs, and a fine crystalline powder with crystal sizes from 0.316 to $0.355 \mu \mathrm{m}$ is formed when activated by an acetate additive and from 0.383 to 0.386 $\mu \mathrm{m}$ when ammonium chloride is added. 
The experimental results allow to make the conclusion about the possibility of choosing an activating additive for CSP based on data on the study of the effect of activators on the crystal growth of various oxides at TVT.

Author Contributions: Conceptualization, Y.I., A.S.; methodology, Y.I.; experimental investigation, Y.I., A.S., M.K. (Maxim Kornyushin); resources, M.K. (Mikhail Kormilicin); data analysis, Y.I., A.S., A.K.; writing—original draft preparation, Y.I., A.S., A.V.; writing—review and editing, V.S. All authors have read and agree to the published version of the manuscript.

Funding: This research received no external funding.

Acknowledgments: The work was supported in part by M.V. Lomonosov Moscow State University Program of Development. The work was carried out with the use of equipment of the Centre of Collective Usage "Joint Educational and Scientific Center for Collective Use" of MIREA—Russian Technological University.

Conflicts of Interest: The authors declare no conflict of interest.

\section{References}

1. Guo, H.; Baker, A.; Guo, J.; Randall, C.A. Protocol for Ultralow-Temperature Ceramic Sintering: An Integration of Nanotechnology and the Cold Sintering Process. ACS Nano 2016, 10, 10606-10614. [CrossRef] [PubMed]

2. Guo, H.; Guo, J.; Baker, A.; Randall, C.A. Hydrothermal-Assisted Cold Sintering Process: A New Guidance for Low-Temperature Ceramic Sintering. ACS Appl. Mater. Interfaces 2016, 8, 20909-20915. [CrossRef] [PubMed]

3. Maria, J.-P.; Kang, X.; Floyd, R.; Dickey, E.C.; Guo, H.; Guo, J.; Baker, A.; Funihashi, S.; Randall, C.A. Cold sintering: Current status and prospects. J. Mater. Res. 2017, 32, 3205-3218. [CrossRef]

4. Chaim, R.; Levin, M.; Shlayer, A.; Estournès, C. Sintering and densification of nanocrystalline ceramic oxide powders: A review. Adv. Appl. Ceram. 2008, 107, 159-169. [CrossRef]

5. Chen, P.-L.; Chen, I.-W. Sintering of Fine Oxide Powders: II, Sintering Mechanisms. J. Am. Ceram. Soc. 1997, 80, 637-645. [CrossRef]

6. Funahashi, S.; Guo, J.; Guo, H.; Wang, K.; Baker, A.L.; Shiratsuyu, K.; Randall, C.A. Demonstration of the cold sintering process study for the densification and grain growth of ZnO ceramics. J. Am. Ceram. Soc. 2017, 100, 546-553. [CrossRef]

7. Guo, J.; Floyd, R.; Lowum, S.; Maria, J.-P.; De Beauvoir, T.H.; Seo, J.-H.; Randall, C.A. Cold Sintering: Progress, Challenges, and Future Opportunities. Annu. Rev. Mater. Res. 2019, 49, 275-295. [CrossRef]

8. Biesuz, M.; Taveri, G.; Duff, A.I.; Olevsky, E.; Zhu, D.; Hu, C.; Grasso, S. A theoretical analysis of cold sintering. Adv. Appl. Ceram. 2020, 119, 75-89. [CrossRef]

9. Ndayishimiye, A.; Sengul, M.Y.; Bang, S.H.; Tsuji, K.; Takashima, K.; De Beauvoir, T.H.; Denux, D.; Thibaud, J.-M.; Van Duin, A.C.; Elissalde, C.; et al. Comparing hydrothermal sintering and cold sintering process: Mechanisms, microstructure, kinetics and chemistry. J. Eur. Ceram. Soc. 2020, 40, 1312-1324. [CrossRef]

10. Kang, X.; Floyd, R.; Lowum, S.; Cabral, M.J.; Dickey, E.C.; Maria, J.-P. Mechanism studies of hydrothermal cold sintering of zinc oxide at near room temperature. J. Am. Ceram. Soc. 2019, 102, 4459-4469. [CrossRef]

11. Ndayishimiye, A.; Largeteau, A.; Mornet, S.; Duttine, M.; Dourges, M.-A.; Denux, D.; Verdier, M.; Gouné, M.; De Beauvoir, T.H.; Elissalde, C.; et al. Hydrothermal Sintering for Densification of Silica. Evidence for the Role of Water. J. Eur. Ceram. Soc. 2018, 38, 1860-1870. [CrossRef]

12. Guo, H.; Baker, A.; Guo, J.; Randall, C.A. Cold Sintering Process: A Novel Technique for Low-Temperature Ceramic Processing of Ferroelectrics. J. Am. Ceram. Soc. 2016, 99, 3489-3507. [CrossRef]

13. Dargatz, B.; Gonzalez-Julian, J.; Bram, M.; Shinoda, Y.; Wakai, F.; Guillon, O. FAST/SPS sintering of nanocrystalline zinc oxide-Part II: Abnormal grain growth, texture and grain anisotropy. J. Eur. Ceram. Soc. 2016, 36, 1221-1232. [CrossRef]

14. Dargatz, B.; Gonzalez-Julian, J.; Bram, M.; Jakes, P.; Besmehn, A.; Schade, L.; Röder, R.; Ronning, C.; Guillon, O. FAST/SPS sintering of nanocrystalline zinc oxide-Part I: Enhanced densification and formation of hydrogen-related defects in presence of adsorbed water. J. Eur. Ceram. Soc. 2016, 36, 1207-1220. [CrossRef]

15. Gonzalez-Julian, J.; Neuhaus, K.; Bernemann, M.; Da Silva, J.P.; Laptev, A.; Bram, M.; Guillon, O. Unveiling the mechanisms of cold sintering of $\mathrm{ZnO}$ at $250{ }^{\circ} \mathrm{C}$ by varying applied stress and characterizing grain boundaries by Kelvin Probe Force Microscopy. Acta Mater. 2018, 144, 116-128. [CrossRef]

16. Grasso, S.; Biesuz, M.; Zoli, L.; Taveri, G.; Duff, A.I.; Ke, D.; Jiang, A.; Reece, M.J. A review of cold sintering processes. Adv. Appl. Ceram. 2020, 119, 115-143. [CrossRef]

17. Ivakin, Y.; Danchevskaya, M.; Kholodkova, A.; Muravieva, G.; Rybalchenko, V. Recrystallization of fine-crystalline barium titanate in low-density water medium. J. Supercrit. Fluids 2020, 159, 104771. [CrossRef]

18. Ivakin, Y.D.; Danchevskaya, M.N. Analysis of Recrystallization of Fine-Crystalline Corundum in a Supercritical Water Medium Using the Lognormal Particle Size Distribution Function. Russ. J. Phys. Chem. B 2018, 12, 1205-1211. [CrossRef] 
19. Ivakin, Y.D.; Danchevskaya, M.N.; Muravieva, G.P. Recrystallization of Zinc Oxide in a Sub- and Supercritical Water Medium. Russ. J. Phys. Chem. B 2019, 13, 1189-1200. [CrossRef]

20. Bagwell, R.B.; Messing, G.L. Effect of Seeding and Water Vapor on the Nucleation and Growth of $\alpha-\mathrm{Al} 2 \mathrm{O} 3$ from $\gamma$-Al2O3. J. Am. Ceram. Soc. 1999, 82, 825-832. [CrossRef]

21. Lazarev, V.B.; Panasyuk, G.P.; Voroshilov, I.L.; Boudova, G.P.; Danchevskaya, M.N.; Torbin, S.N.; Ivakin, Y.D. New Ecologically Pure Technologies of Fine-Crystalline Materials. Ind. Eng. Chem. Res. 1996, 35, 3721-3725. [CrossRef]

22. Danchevskaya, M.; Torbin, S.; Muravieva, G.; Ovchinnikova, O.; Ivakin, Y. Synthesis and investigation of crystalline modifications of silicon dioxide. React. Solids 1988, 5, 293-303. [CrossRef]

23. Danchevskaya, M.N.; Ivakin, Y.D.; Torbin, S.N.; Panasyuk, G.P.; Belan, V.N.; Voroshilov, I.L. Scientific basis of technology of fine-crystalline quartz and corundum. High Press. Res. 2001, 20, 229-239. [CrossRef]

24. Branson, D.L. Kinetics and Mechanism of the Reaction Between Zinc Oxide and Aluminum Oxide. J. Am. Ceram. Soc. 1965, 48, 591-595. [CrossRef]

25. Ivakin, Y.D.; Danchevskaya, M.N.; Ovchinnikova, O.G.; Muravieva, G.P. Thermovaporous synthesis of fine crystalline gahnite $\left(\mathrm{ZnAl}_{2} \mathrm{O}_{4}\right.$ ). J. Mater. Sci. 2006, 41, 1377-1383. [CrossRef]

26. Kholodkova, A.; Danchevskaya, M.; Ivakin, Y.; Smirnov, A.; Ponomarev, S.; Fionov, A.; Kolesov, V. Solid state synthesis of barium titanate in air and in supercritical water: Properties of powder and ceramics. Ceram. Int. 2019, 45, 23050-23060. [CrossRef]

27. Cunha-Duncan, F.N.; Bradt, R.C. Synthesis of Magnesium Aluminate Spinels from Bauxites and Magnesias. J. Am. Ceram. Soc. 2004, 85, 2995-3003. [CrossRef]

28. Yang, L.; Xiao, G.; Ding, D.; Li, P.; Lv, L.H.; Yang, S.L. Soild-phase synthesis of MgAl2O4 powder in reducing atmosphere: Effects of alumina sources and addition of carbon black. Mater. Res. Express 2019, 6, 045007. [CrossRef]

29. Danchevskaya, M.N.; Ivakin Yu., D.; Muravieva, G.P. Synthetic Magnesium Spinel-Raw Material for Optical Ceramics. In Proceedings of the 14th European Meeting on Supercritical Fluids, Marseille, France, 18-21 May 2014.

30. Kayani, Z.N.; Saleemi, F.; Batool, I. Effect of calcination temperature on the properties of ZnO nanoparticles. Appl. Phys. A 2015, 119, 713-720. [CrossRef]

31. Wang, M.; Zhou, Y.; Zhang, Y.; Hahn, S.H.; Kim, E.J. From $\mathrm{Zn}(\mathrm{OH})_{2}$ to ZnO: A study on the mechanism of phase transformation. CrystEngComm 2011, 13, 6024-6026. [CrossRef]

32. Mukhopadhyay, S.; Das, P.P.; Maity, S.; Ghosh, P.; Devi, P.S. Solution grown ZnO rods: Synthesis, characterization and defect mediated photocatalytic activity. Appl. Catal. B Environ. 2015, 165, 128-138. [CrossRef]

33. Ivakin, Y.D.; Smirnov, A.V.; Tarasovskii, V.P.; Rybal'Chenko, V.V.; Vasin, A.A.; Kholodkova, A.A.; Kormilitsin, M.N. Cold Sintering of ZnO Ceramic in Water Medium: Test Demonstration. Glas. Ceram. 2019, 76, 210-215. [CrossRef]

34. Egbuchunam, T.; Balkose, D. Effect of Supercritical Ethanol Drying on the Properties of Zinc Oxide Nanoparticles. Dry. Technol. 2012, 30, 739-749. [CrossRef]

35. Vukalovich, M.P.; Rivkin, S.L. Thermophysical Properties of Water and Water Vapor; Mashinostroyeniye: Moscow, Russia, 1967; pp. $1-160$.

36. Ali, M.; Winterer, M. ZnO Nanocrystals: Surprisingly 'Alive'. Chem. Mater. 2010, 22, 85-91. [CrossRef]

37. Thurber, A.P.; Alanko, G.A.; Beausoleil, G.L.; Dodge, K.N.; Hanna, C.B.; Punnoose, A. Unusual crystallite growth and modification of ferromagnetism due to aging in pure and doped ZnO nanoparticles. J. Appl. Phys. 2012, 111, 7. [CrossRef]

38. Nie, J.; Zhang, Y.; Chan, J.M.; Huang, R.; Luo, J. Water-assisted flash sintering: Flashing ZnO at room temperature to achieve $\sim 98 \%$ density in seconds. Scr. Mater. 2018, 142, 79-82. [CrossRef]

39. Dargatz, B.; Gonzalez-Julian, J.; Guillon, O. Anomalous coarsening of nanocrystalline zinc oxide particles in humid air. J. Cryst. Growth 2015, 419, 69-78. [CrossRef]

40. Meyer, B.; Marx, D.; Dulub, O.; Diebold, U.; Kunat, M.; Langenberg, D.; Wöll, C. Partial Dissociation of Water Leads to Stable Superstructures on the Surface of Zinc Oxide. Angew. Chem. Int. Ed. 2004, 43, 6641-6645. [CrossRef]

41. Wang, Y.; Muhler, M.; Wöll, C.; Wöll, C. Spectroscopic evidence for the partial dissociation of $\mathrm{H}_{2} \mathrm{O}$ on $\mathrm{ZnO}(10 \overline{1} 0)$. Phys. Chem. Chem. Phys. 2006, 8, 1521-1524. [CrossRef]

42. Kenmoe, S.; Biedermann, P.U. Water aggregation and dissociation on the $\mathrm{ZnO}(10 \overline{1} 0)$ surface. Phys. Chem. Chem. Phys. 2017, 19, 1466-1486. [CrossRef]

43. Newberg, J.T.; Goodwin, C.; Arble, C.; Khalifa, Y.; Boscoboinik, J.A.; Rani, S. ZnO(10̄̄0) Surface Hydroxylation under Ambient Water Vapor. J. Phys. Chem. B 2017, 122, 472-478. [CrossRef] [PubMed]

44. Yu, X.; Schwarz, P.; Nefedov, A.; Meyer, B.; Wang, Y.; Wöll, C. Structural Evolution of Water on ZnO(100): From Isolated Monomers via Anisotropic H-Bonded 2D and 3D Structures to Isotropic Multilayers. Angew. Chem. Int. Ed. 2019, 58, 17751-17757. [CrossRef] [PubMed]

45. Quaranta, V.; Hellström, M.; Behler, J. Proton-Transfer Mechanisms at the Water-ZnO Interface: The Role of Presolvation. J. Phys. Chem. Lett. 2017, 8, 1476-1483. [CrossRef] [PubMed]

46. Ramabhadran, R.O.; Mayhall, N.J.; Raghavachari, K. Proton Hop Paving the Way for Hydroxyl Migration: Theoretical Elucidation of Fluxionality in Transition-Metal Oxide Clusters. J. Phys. Chem. Lett. 2010, 1, 3066-3071. [CrossRef] 